\section{Violência doméstica contra mulheres e a atuação profissional na atenção primária à saúde: um estudo etnográfico em Matinhos, Paraná, Brasil}

\author{
Domestic violence against women and professional \\ intervention in primary healthcare: an etnographic \\ study in Matinhos, Paraná State, Brazil \\ Violencia doméstica contra mujeres y la actuación \\ profesional en la atención primaria a la salud: un \\ estudio etnográfico en Matinhos, Paraná, Brasil
}

Marcos Claudio Signorelli 1

Daniela Auad 2

Pedro Paulo Gomes Pereira ${ }^{3}$
1 Universidade Federal do
Paraná, Curitiba, Brasil.
2 Universidade Federal de
Juiz de Fora, Juiz de Fora,
Brasil.
3 Universidade Federal de São
Paulo, São Paulo, Brasil.
Correspondência
M. C. Signorelli
Universidade Federal do
Paraná.
Rua Jaguariaíva 512, Gab06,
Matinhos, PR
83260-000, Brasil.
signorelli.marcos@gmail.com

\begin{abstract}
Domestic violence has multiple repercussions on women's health and raises a challenging agenda for health professionals in Brazilian Unified National Health System (SUS). The aim of this study was to analyze how health professionals treat these women, problematizing the notion of acolhimento (receptiveness or openness to patients). A qualitative ethnographic research approach was used with health professionals from a primary care unit (PHU) in Matinhos, Paraná State, Brazil. The study revealed care that was focused on: (1) biologizing principles, with a focus on physical lesions and medicalization and (2) dialogue, active listening, psychosocial questions, and establishment of ties, especially featuring community health agents in this approach. The limited official local structure for handling domestic violence justifies treatment oriented by the grammar of acolhimento, recommended by the SUS, described in the literature, and verbalized in the $P H U$, but rarely problematized. This article thus proposed to contribute to this debate, not by establishing prescriptions for action, but by raising questions and mainly highlighting and translating the voices of those who deal with this challenge on a daily basis.
\end{abstract}

Domestic Violence; Violence Against Women; Gender and Health; User Embracement

\section{Resumo}

A violência doméstica provoca múltiplas repercussões na saúde das mulheres e gera desafiadora agenda para os profissionais do SUS. Objetivou-se analisar como profissionais de saúde atendem tais mulheres, problematizando a noção de acolhimento em saúde. Adotou-se pesquisa qualitativa e aproximação etnográfica com profissionais de uma unidade básica de saúde (UBS) de Matinhos, Paraná, Brasil. A pesquisa revelou atendimentos centrados em: (1) preceitos biologizantes, com foco em lesões físicas e medicalização; (2) diálogo, escuta ativa, questões psicossociais e estabelecimento de vínculos, destacando-se agentes comunitários de saúde nesta abordagem. A escassez de estrutura local oficial para manejo da violência doméstica enseja atuação inscrita sob a gramática do acolhimento, preconizada pelo SUS, descrita pela literatura, verbalizada na UBS, mas pouco problematizada. Com este artigo buscou-se, portanto, contribuir com tal debate, não no estabelecimento de prescrições, porém no levantamento de indagações e principalmente visibilizando e traduzindo vozes de quem trabalha diuturnamente com esse desafio.

Violência Doméstica; Violência Contra a Mulher; Gênero e Saúde; Acolhimento 


\section{Introdução}

A violência atinge homens e mulheres de diferentes maneiras e em diversas etapas da vida, provocando múltiplas repercussões e gerando desafiadora agenda para o sistema de saúde. A Organização Mundial da Saúde (OMS) estima que no mundo, uma em cada três mulheres é, já foi, ou será vítima de violência doméstica 1. Embora de difícil quantificação em valores absolutos, algumas pesquisas, em especial aquelas de caráter multicêntrico ${ }^{2,3}$, vêm relatando que esse problema é ainda mais comum nos chamados "países em desenvolvimento", estando o Brasil neste grupo.

Para compreender a violência doméstica contra mulheres é fundamental o entendimento da categoria de análise gênero. Neste estudo, são adotados como referenciais de gênero os trabalhos desenvolvidos por Joan Scott 4 e Christine Delphy ${ }^{5}$. Scott 4 propõe o gênero como elemento constitutivo de relações sociais construídas sobre as diferenças percebidas entre os sexos, sendo ele um primeiro modo de dar significado às relações de poder. Delphy 5 complementa que gênero é um produto social que constrói o sexo, sugerindo que não é o gênero que é construído sobre a base da diferença do sexo biológico, mas o sexo biológico é socialmente construído por causa da existência do gênero. A diferença entre homens e mulheres é um fato anatômico que não teria nenhuma significação, não fossem os arranjos de gênero vigentes, que reconhecem a diferença, hierarquizando-a. E para a autora, transformar essa diferença em desigualdade é um ato social.

A intersecção entre violência e gênero é também abordada por diversos autores 6,7 . As configurações englobam "violência física" que compreende lesões e danos à integridade física das mulheres; "violência psicológica", que inclui humilhações, isolamento, desprezos e intimidações; "violência patrimonial", que se concretiza em roubo, retenção ou danos aos bens materiais, recursos e/ou documentos; "violência verbal", caracterizada por xingamentos, ofensas, ameaças e injúrias; e "violência sexual", caracterizada por relações sexuais forçadas ou práticas sexuais não consentidas.

Com base nessas manifestações, muitas mulheres aportam no Sistema Único de Saúde (SUS) buscando cuidado e, por diferentes razões, nem sempre relatam a causa de seus agravos. Nem sempre os/as profissionais de saúde relacionam as lesões observadas à violência doméstica. Em alguns casos, essas mulheres são denominadas pelos/as profissionais de saúde como "poliqueixosas", dada a diversidade de sinais e sintomas físicos e psicológicos, muitas vezes difíceis de serem localizados, explicados, diagnosticados e tratados ${ }^{8}$. São mais suscetíveis a uma série de agravos de saúde, como dores crônicas, problemas ginecológicos e psicológicos, num quadro descrito por McCauley et al. 9 como Battering Syndrome ou "Síndrome da Mulher Espancada". A esse cenário ainda somam-se as implicações familiares e relacionadas ao trabalho. Consequentemente, essas mulheres buscam, de maneira mais frequente e recorrente, por assistência nos serviços de saúde.

Dessa maneira, lançar o olhar sobre os modos com que operam essas interações, que envolvem mulheres, profissionais e o SUS, em distintos cenários dos serviços, pode ser uma alternativa para tentar compreender um pouco mais sobre as diferentes facetas desse complexo panorama. Esse pode ser um dos alicerces para a construção, proposição e implementação de políticas públicas e estratégias de minimização dessa problemática, pensando-se especialmente no âmbito da saúde coletiva.

Assim, com base nessa conjuntura, caracterizada por mulheres que demandam cuidado em saúde e por profissionais de saúde que necessitam atender mulheres em situação de violência doméstica, foi proposto este trabalho. Objetivouse analisar como profissionais da atenção primária à saúde atendem às mulheres em situação de violência doméstica, problematizando a noção de acolhimento em saúde. Por meio de pesquisa qualitativa de cunho etnográfico, investigou-se a atuação de profissionais de saúde da unidade básica de saúde (UBS) Tabuleiro no Município de Matinhos, litoral paranaense, diante de casos de violência doméstica contra mulheres; e se a abordagem de cuidado em saúde é fundamentada unicamente em aspectos da biomedicina 10, com destaque para aspectos biologizantes e manifestações físicas da violência (como hematomas, fraturas, cortes etc.), ou se o cuidado também leva em conta outras dimensões, albergadas sob uma categoria que vem sendo nomeada como "acolhimento em saúde" 11,12.

\section{Metodologia}

Este trabalho baseou-se em metodologia qualitativa de estudo 13 , por meio de proposta de pesquisa etnográfica, segundo Geertz 14 . Tal metodologia objetiva prover conhecimento aprofundado e apropriação de significados, visando a compreender as relações entre profissionais de saúde e mulheres em situação de violência doméstica, no cenário da atenção primária à saúde. As observações e vozes que emergiram do campo 
foram categorizadas tematicamente e cotejadas com discursos dos estudos de gênero, de violência, e do campo da saúde coletiva, no que tange aos modos de atendimento e cuidado por profissionais de saúde.

O contato do autor principal com a UBS Tabuleiro data desde 2006, por meio da supervisão de estágios curriculares em Saúde Coletiva, realizados na unidade por acadêmicos da Universidade Federal do Paraná (UFPR), da qual é docente. A etnografia foi conduzida ao longo de sete meses (junho de 2009 a janeiro de 2010) mediante o acompanhamento da rotina diária da UBS, que compreende a população de três bairros, em área coberta por três equipes de saúde da família (ESF). Geertz ${ }^{14}$ argumenta que etnografia não é definida pelas técnicas que emprega, como entrevistas, mas por um tipo particular de esforço intelectual referido como uma "descrição densa”. Tipicamente obtida por meio de imersão na vida diária do grupo, focalizam-se detalhes e backgrounds, almejando explicar modos de vida e padrões de significado.

A pesquisa de campo consistiu em observação participante, registros em caderno de campo, entrevistas e acompanhamento da rotina cotidiana de profissionais da UBS. Dentre dezenas de frequentadores/as da UBS abordados no período, quinze interlocutores foram considerados informantes-chave para os objetivos deste estudo: agentes comunitários de saúde (ACS), enfermeiras, fisioterapeutas e também mulheres identificadas por profissionais como vítimas de violência doméstica. As entrevistas e anotações do caderno de campo foram transcritas, codificadas e realizada análise temática de categorias emergentes do campo. Para escrever a etnografia, é importante que o pesquisador se aproprie dos dados coletados em campo, dando um sentido à suas experiências 14 .

Garantiu-se o anonimato e confidencialidade dos interlocutores, sendo adotados pseudônimos e acordo do Termo de Consentimento Livre e Esclarecido. A pesquisa seguiu todos os procedimentos éticos, tendo sido aprovada pelo Comitê de Ética em Pesquisa da Universidade Federal de São Paulo.

\section{Resultados e discussão}

O litoral é uma das regiões menos desenvolvidas do Paraná, analisando-se indicadores socioeconômicos e de saúde. Matinhos possui aproximadamente 30 mil habitantes, número decuplicado durante a temporada de verão. A UBS Tabuleiro compreende dois territórios distintos: um balneário (Caiobá), onde famílias abastadas do es- tado possuem residências de veraneio, que fica ermo fora da temporada; e um bairro popular (Tabuleiro), que inclui uma ocupação territorial (Vila Nova), onde vive grande parte da população que trabalha para quem vem passar as férias no balneário. Nesse bairro, a maioria das ruas não tem pavimentação, há falta de saneamento, ligações elétricas irregulares, casas improvisadas e muitos animais soltos. Diante desse cenário contrastante, pode-se ponderar sobre as relações entre sujeitos. De modo algum há pretensão de associar direta e exclusivamente pobreza com violência doméstica, até porque se manifesta em todos os extratos sociais. Porém, assim como em outras regiões brasileiras, marcadas por conjunturas semelhantes, emergem sérios problemas, incluindo-se as desigualdades de gênero, que tem a violência doméstica contra mulheres uma das expressões mais significativas.

Contudo, a escassez de dados sistematizados cria uma lacuna no dimensionamento do problema, devido principalmente à ausência de sistemas integrados de notificação de casos. $\mathrm{Na}$ região não há Delegacia Especializada de Atendimento à Mulher (DEAM), tampouco centros de referência no atendimento às mulheres. Tais dados também não constam no DATASUS (Departamento de Informática do SUS), apesar de recentes avanços na legislação, forçando a notificação compulsória. A maioria dos municípios brasileiros não adotou como prática essa estratégia de visibilidade para o problema. Todavia, os relatos extraoficiais são numerosos. Particularmente, diversos casos foram oriundos: de reuniões com gestores e profissionais de saúde, em projeto de pesquisa/extensão universitária acerca do tema, desenvolvido previamente no local (2007-2009) 15; do contato com a UBS na supervisão de estágios em Saúde Coletiva, do curso de Fisioterapia da UFPR (desde 2006); da participação no Conselho Municipal de Saúde de Matinhos (2009-2011).

Um fato relevante nos discursos de profissionais e usuárias da UBS Tabuleiro é que, os casos de violência doméstica contra mulheres são maiores fora da temporada de verão, quando homens ficam ociosos e sem trabalho. No entanto, apesar de tantos relatos e repercussões desse agravo à saúde, grande parte dessas mulheres não revela sua condição aos profissionais, por sentimentos como medo, culpa e vergonha, fato difundido na literatura 16,17,18 e também evidenciado nos discursos de muitas/os profissionais de Matinhos.

Já os casos que são materializados na atenção primária à saúde de Matinhos, com base neste estudo, considerou-se pertinente agrupá-los em duas distintas situações de violência doméstica, 
embora interconectadas uma à outra: "circunstâncias agudas" (ou emergentes) e "conjunturas crônicas" (ou recorrentes). As "circunstâncias agudas" dizem respeito a ocorrências recentes, que logo em seguida surgem no SUS, ou situações de violência doméstica que ocorrem durante os atendimentos, em visitas domiciliares, por exemplo. Uma dessas situações foi narrada por uma fisioterapeuta e será descrita adiante.

Em circunstâncias agudas, os agravos à saúde são advindos de atos recém-cometidos, ou seja, em estado latente. Geralmente estão associadas à violência física e/ou sexual que inscrevem lesões nos corpos, atingindo também aspectos psicossociais. Elas se dirigem motivadas por traumas agudos, frequentemente com sinais físicos visíveis e buscando atendimento em unidades de emergência, como pronto-atendimentos e/ou hospitais, portanto fora dos domínios da atenção primária à saúde. Em Matinhos essa lógica predomina e dificilmente situações agudas de violência doméstica aportam na UBS. Entretanto, na atenção primária à saúde, tais situações podem estar mais próximas dos profissionais que atuam na ESF, já que adentram no espaço doméstico das mulheres, arena da violência doméstica.

Já as condições crônicas de violência doméstica dizem respeito aos agravos que as mulheres desenvolvem em decorrência da violência doméstica repetida, recorrente e ressonante em suas vidas. Elas buscam os serviços de maneira bastante frequente na UBS Tabuleiro, porém, majoritariamente, não se queixam de sua condição, nem se consideram como vítimas de violência doméstica ${ }^{8}$. Aludem a outras queixas, que são direta ou indiretamente relacionadas aos atos violentos. Elas aportam corriqueiramente na atenção primária à saúde via UBS e/ou são visitadas por profissionais da ESF. Na maioria das vezes, não comentam sobre sua condição, ao menos num primeiro momento. Teria então, o/a profissional de saúde a responsabilidade de identificar, acolher e encaminhar os casos?

Alguns episódios surgiram ao longo da pesquisa de campo, por meio do vínculo estabelecido, como o revelado por Dona Marlene, 65 anos, casada com Sebastião e convivendo com o problema há 40 :

"Ele já me bateu muitas vezes... já me deixou roxa... aqui no braço. E já até desviou a minha coluna do lugar... Ah, uma vez... faz tempo... ele me bateu, me jogou no chão... e depois bateu mais ainda... [...] Quando fui para o hospital, na época, disse que tinha caído da escada. Agora eu sempre sinto essa dor nas costas... Desde aquela vez..." (Dona Marlene, usuária da UBS).

Dona Marlene, assim como muitas mulheres vítimas de violência doméstica daquela rea- lidade, não expõe a priori a causa dos sintomas decorrentes de agressões físicas às/aos profissionais de saúde, principalmente em ambientes hospitalares, marcados por relações mais breves com profissionais. Assim como ela, muitas dizem que caíram ou sofreram acidentes. Entretanto, dependendo da relação com a/o profissional, particularmente se mais duradoura e com vínculos, quando questionadas mais especificamente, muitas acabam relatando. Chamou atenção nesse caso (assim como em outros, naquela realidade) a confiança depositada por Dona Marlene em sua ACS, revelando-lhe seu problema. Segundo Alpert 19, profissionais da saúde têm função essencial na prevenção primária, identificação e intervenção precoce em casos de violência doméstica. Porém, nem todos os profissionais atentam ao fato, conforme relatou Sônia, ACS de 43 anos, há dois na UBS:

"A mulher [vítima de violência] sempre está com algum problema. E a gente não consegue descobrir. Vai no médico, faz exame, vai no posto pedem exame, encaminha pra cá, encaminha pra lá e... não descobrem. Com o tempo, a gente [ACS] que está frequentando a casa dela, a gente descobre que ela tem problemas na família... de violência! E isso acarreta doenças pra ela... E o profissional, eu via que não tinha a capacidade de atender aquela necessidade da mulher. Nem com informações..." (Sônia, ACS).

Aqui sobressai que ACS, por frequentarem as casas numa relação mais próxima com as mulheres, percebem a violência doméstica, bem como as repercussões em sua saúde, mesmo sem a verbalização delas. Já outros/as profissionais da UBS, sobretudo médicos/as, se atrelam a exames que trazem dados inconclusivos, categorizam os achados como "queixas difusas" e não detectam o problema. Diversos autores 20,21,22 relatam que profissionais de saúde têm muita dificuldade em lidar com violência doméstica. É um problema complexo, não sendo passível ser abordado plenamente pelo viés da biomedicina, que preconiza tratamento médico-centrado, exames e extermínio de lesões e dores físicas. Para Warshaw 20, profissionais devem extrapolar esse modelo tradicional, agregando fatores como sensibilidade pessoal e comprometimento social, tornando-se corresponsáveis, junto com as mulheres, na identificação e minimização da violência doméstica.

Muitos estudos têm evidenciado que profissionais da saúde não recebem capacitação adequada para lidar com violência doméstica 19,20. Situação idêntica ocorre com os profissionais de Matinhos que, exceto uma enfermeira, expuseram não ter recebido sensibilização sobre o cuidado de mulheres vítimas de violência doméstica. Entretanto, apesar de lacunas na formação e 
pouca estrutura local, muitos/as profissionais da UBS demonstraram estar atentos ao bem-estar das mulheres (como será descrito adiante), embora em abordagens tímidas, não institucionalizadas e que não atendem a todos os anseios da população.

A violência doméstica contra mulheres é percebida pelos/as profissionais da UBS de modo abrangente. Não é vista apenas como sinônimo de trauma físico, focalizando o corpo ou queixas biológicas. Pelo contrário, a maioria absoluta relatou noções de violência doméstica muito mais ligadas a aspectos socioemocionais. Definem o problema relacionando aos abusos e agressões verbais, psicológicas, morais e inclusive, patrimoniais, sem contudo, negar lesões físicas.

Apesar de profissionais de Matinhos não verbalizarem a categoria gênero, realçaram algumas diferenças percebidas entre homens e mulheres daquela comunidade. Para os profissionais, um aspecto evidente é que a violência doméstica contra mulheres praticada por filhos, netos e pais/padrastos também é tão frequente quanto aquela praticada por maridos/companheiros. Ou seja, para eles/as a violência doméstica aparece predominantemente como fruto de conflitos nas relações entre homem e mulher, incluindo companheiro/companheira, filho/mãe, pai/ filha, padrasto/enteada, neto/avó. Isso denota referenciais a partir de relações de gênero, embora nem a categoria gênero nem os desdobramentos com base nas suas desigualdades foram mencionados.

Outro destaque das/dos profissionais é que naquele território a violência doméstica não recai somente sobre mulheres, sendo comuns casos de violência familiar e propagação intergeracional da violência. Uma das ACS revela que: "há um pai que mantém relações sexuais com a mãe e a filha". A transmissão intergeracional da violência vem adquirindo significativo reconhecimento em estudos que sinalizam (embora não condicionem) associação entre exposição à violência durante a infância e vitimização ou perpetuação da violência em relações futuras 23 . A reprodução de comportamentos violentos ao longo de gerações tem sido debatida ${ }^{24}$, sendo apontada com maior probabilidade de manifestação em sujeitos que foram vítimas ou testemunharam comportamentos violentos na família de origem.

A enfermeira Helga, 26 anos, comenta sobre violência doméstica contra meninas e meninos, destacando ser comum apresentarem marcas no corpo, sugestivas de atividade sexual, sobretudo na região menos privilegiada do bairro. Segundo Helga, profissionais de saúde estão definindo uma estratégia naquela área, explicando que não seria denunciar diretamente os abusos, pois pro- fissionais ficam marcadas/os e podem se tornar vítimas. Em um caso que acompanhamos, uma ACS denunciou situação envolvendo abuso sexual infantil ao Conselho Tutelar e a identidade da ACS foi revelada, passando a sofrer ameaças do agressor. A estratégia visa a definir um plano para atender crianças, conjuntamente com ACS assistência social e psicólogo, e conclamar vizinhos/comunidade durante as visitas para que ajudem, denunciando ao Conselho Tutelar.

Assim, caberia questionar limites e possibilidades de profissionais de saúde diante de situações tão complexas. Como é possível cuidar das pessoas sob seu cuidado sem arriscar sua própria segurança? Qual a importância da ampliação do olhar, para além das queixas físicas e resolução de sinais/sintomas? Que particularidades podem ser diferenciais no atendimento às mulheres convivendo com violência doméstica? Seria importante que profissionais atentem aos sinais, buscando, mesmo sem o relato, identificar ativamente tais mulheres? E como manejar sem limitar-se à medicalização dos casos? Não se trata de negligenciar atenção a queixas biológicas ou procedimentos fundamentados na biomedicina, como exames, tratamento farmacológico e encaminhamentos a especialistas. Sabemos dessa relevância e da significância em identificar e notificar casos encontrados, para que constem nos registros epidemiológicos. Mas haveria outras possibilidades na abordagem em saúde que não balizem o atendimento em queixas físicas e tendências biologizantes? O que profissionais da UBS Tabuleiro podem contribuir no vislumbre de outras perspectivas de atuação?

Nessa direção, autores 25,26,27,28,29 apontam o acolhimento como uma possibilidade de atenção à saúde, que nesse caso poderia contribuir no atendimento de mulheres em situação de violência doméstica. Segundo Ayres 30 , o acolhimento tem sido atribuído como um dispositivo tecnológico nas propostas de humanização da saúde, possibilitando capacidade de ausculta e diálogo entre profissionais e usuários. Entretanto, tal noção é pouco problematizada e necessita de reflexões, tanto conceituais quanto empíricas, sobre suas potencialidades e desafios.

Oliveira et al. 25 assinalam aspectos relacionados ao acolhimento em locais de referência, que atendem a mulheres que sofreram violência sexual em São Paulo, sendo descrito como uma relação solidária, respeitosa, acolhedora, que trabalhadores e serviços de saúde, como um todo, estabelecem com usuárias que neles aportam. Com base nessas acepções, é possível assinalar uma situação durante visita domiciliar, narrada pela fisioterapeuta Carminha, 26 anos, que na época trabalhava há dois na UBS: 
"Uma senhora era frequentemente espancada pelo filho, usuário de drogas. Numa ocasião eu estava na casa dela, atendendo o marido acamado e o filho a ameaçou com uma faca... Tive que ir pra cima dele, com minha prancheta, que era a única coisa que tinha em mãos... A mulher ficou atrás de mim. Então, fiquei entre o agressor e a agredida... Se não tivesse feito isso, acho que ele teria matado ela... [...] Levei o caso pro prefeito. Ele foi preso. [...] Encaminhei ela [não oficialmente, mas por amizade] pra assistente social, enfermeira e psicóloga. Nós costumávamos ir juntas cuidar dela... Ajudei ela a cuidar de sua autoestima, levava batom e maquiagem pra ela... Também estimulava ela a pensar mais positivamente sobre si mesma, sobre seu bem-estar" (Carminha, fisioterapeuta).

Esse caso é ilustrativo para mostrar o acolhimento, pois a fisioterapeuta, incumbida inicialmente de atender apenas o pai/marido, diante da situação de violência doméstica praticada pelo filho contra a mãe, ampliou seu foco de cuidado para a mulher. Nesse caso, evidencia-se a "acessibilidade universal", defendida por autores 11,12 como integrante da proposta de acolhimento, e realçado pela ampliação do cuidado a quem talvez não demandasse por atendimento, por medo/vergonha, como explicitado anteriormente. Na narrativa, evidenciaram-se elementos de uma abordagem "usuário-centrada", outro ponto argumentado pelos autores, corroborado por meio da preocupação com as necessidades da mulher: autoestima, relacionamentos e vida social. Carminha ainda conclamou a atuação de equipe interprofissional para intervir conjuntamente, deslocando a abordagem médico-centrada, focada em exames e medicamentos, para ações centradas na mulher, com participação de toda equipe. Desse modo, é possível inferir que acolhimento pressupõe estabelecimento de vínculos, centralidade nas pessoas (não em procedimentos) e foco além de questões biológicas, considerando a complexidade social das pessoas.

Conforme descrito pela fisioterapeuta, tal modo interdisciplinar de abordagem não é institucionalizado no SUS naquela realidade. Os encaminhamentos a outras/os profissionais são feitos com base no relacionamento entre profissionais, não como rotina estabelecida. $\mathrm{O}$ atendimento de Carminha desburocratizou o processo, deslocando a centralidade das fichas de encaminhamento e referência/contrarreferência para ações voltadas para as necessidades da mulher. Esse quesito é descrito como "projetos terapêuticos individualizados" (Silva-Júnior, 2001, apud Camargo Jr. 31). Para o autor, esse componente deve integrar a proposta de acolhimento, que é definido como o tratar toda a demanda, dando respostas aos demandantes; envolve discrimi- nar riscos, encaminhando os casos às opções de intervenção e considerando a possibilidade de construção de projetos terapêuticos individualizados. Isso de certo modo se contrapõe à ideia de "rotinas (pré)estabelecidas para todos casos" ou "protocolos terapêuticos", preconizados para vítimas de violência doméstica em algumas redes. O caso de Carminha nos adverte para pensar os protocolos como estratégias generalizantes, pautadas numa visão fragmentada do corpo, visando a medicar para aliviar sintomas, sem considerar o emaranhado de fatores de cada caso.

Alguns desses protocolos consistem em, após sofrer violência doméstica e aportar no SUS, a mulher deve seguir um itinerário de peregrinação dentro do sistema, incluindo consultas e exames em UBS, Unidades de Pronto Atendimento, Instituto Médico-Legal, Centros de Referência Especializada, Centros de Atenção Psicossocial e DEAM. Isso não deve ser advertido como negativo, afinal tal estrutura de suporte é fundamental. Todavia, pensando-se na vítima, essa odisseia no sistema pode se tornar uma via crucis, inibindo/desmotivando-a de levar seu cuidado adiante. Ela terá de recorrer a diferentes instituições, passar tempo em filas e se expor a diferentes profissionais, que muitas vezes não são qualificados para questão tão delicada, nem se comunicam a respeito do caso. Consequentemente, ela regurgitará o caso diversas vezes, revivendo momentos angustiantes a cada encontro, que acabam por evocar sentimentos ruins e gerar mais sofrimento.

Silva-Júnior et al. 26 também alertam sobre a dificuldade dos profissionais de saúde em lidar com sofrimentos das/os usuárias/os. Preferem lidar com doenças, que possuem referências estabelecidas pela biomedicina e pontos de intervenção sobre lesões detectadas. E acrescenta que predomina uma ideia de encaminhar as pessoas a outros profissionais (especialistas), transferindo a responsabilidade do cuidado. Predomina a ênfase em procedimentos, e a incapacidade de produzir núcleos comuns de discussão dos casos produzem visões compartimentalizadas, desfocando a centralidade do cuidado nas pessoas. $\mathrm{O}$ esforço em constituir foco comum, pautado no diálogo com usuárias/os e entre profissionais é um desafio para as equipes, o que coaduna com nossa experiência em Matinhos. Em "condições crônicas de violência doméstica" a transferência de responsabilidade ou omissão dos/das profissionais pode ser mais comum, colocando o problema secundariamente e tratando apenas sinais/sintomas. Entretanto, nas "circunstâncias agudas", como o caso explicitado pela fisioterapeuta, essa "não assunção" da/o profissional como mediador/a e cuidador/a torna-se difícil. 
Seria embaraçoso esquivar-se em tais momentos tão críticos, em que a fisioterapeuta assumiu a função de mediadora, colocando em risco sua própria segurança.

Os/as profissionais de saúde de Matinhos apresentam pouca nitidez conceitual a respeito do acolhimento, mas diversos aspectos propostos na literatura a respeito do tema vêm sendo colocados em prática, tal como o estabelecimento de diálogos e redes de conversações, apontados por Teixeira 27 . Muitos/as profissionais citam o termo com frequência, mas quando indagados/as sobre o que entendem por "acolhimento em saúde" e sobre sua intersecção com mulheres vítimas de violência doméstica, relacionam com provimento de abrigo; ou com terapia de grupo, nomeando como "acolhimento psicológico"; ou ainda "acolhimento econômico", visando a prover recursos econômicos emergenciais, trabalho e autonomia financeira às mulheres. Esses quesitos revelam diferentes olhares sobre o tema, em processo de lapidação conceitual. Desse modo ouvir profissionais que estão em contato direto com mulheres sobre suas considerações em torno desse enunciado, torna-se imprescindível para iluminar teoria e práticas do acolhimento.

Contudo, num sistema que preconiza o acolhimento por meio de diretrizes/políticas de saúde, alguns profissionais (especificamente um ACS e uma enfermeira) não atentaram para essa questão. Focavam seu atendimento em abordagens medicalizantes, transformando todas as condições de saúde em procedimentos médicos que podem ser examinados, diagnosticados e tratados sob óticas farmacologizantes. Já a maioria dos/das profissionais que vislumbraram além das manifestações biologizantes das mulheres, como o caso descrito pela fisioterapeuta, ao perceberem que o sistema não lhes dá suporte acabam muitas vezes sofrendo, junto com as mulheres. A ACS Sônia, adiciona nesse sentido:

"Teve uma moça que teve um neném e foi para casa. O marido usava crack, tinha mais duas crianças, e ela estava apanhando, ele até trancou ela em casa. Fui com a enfermeira e tiramos ela levamos para um hotel até arrumar uma casinha. Ela arrumou casa, emprego, conseguimos... nós ajudamos com comida, compramos cesta básica, arrumamos um hotelzinho para ela ficar [...] Nós pagamos... do nosso bolso. Acho que o que sensibilizou foi a criança recém nascida!" (Sônia, ACS).

Portanto, o termo acolhimento deve ser observado com cautela, já que o SUS preconiza sua efetivação nas redes, mas há parca estrutura de suporte aos profissionais para que possam concretizá-lo. Como exemplificado antes, isso acaba gerando angústias aos profissionais, pois na ânsia de acolher acabam se frustrando, porque o sistema não lhes respalda, tornando-se impossível acolher a todas/os.

Outra questão relativa ao acolhimento, é que não se restringe ao momento de entrada no sistema, nem se limita à recepção. Dá-se no continuum da interação entre usuários/as e serviços, em todas as oportunidades que houver possibilidade de escuta e diálogo 27 . Isso fica evidente nas duas situações descritas anteriormente, tanto no caso da fisioterapeuta quanto da ACS. Para Teixeira 27 , o funcionamento dessa rede depende sobremaneira do primeiro contato das pessoas no serviço, primordial na investigação/elaboração/negociação das necessidades. O desfecho de ações pode depender muito desse primeiro momento, que na atenção primária à saúde em Matinhos é realizado majoritariamente por ACS nas visitas domiciliares. Dependendo da abordagem, muitas/os nem seguem adiante no sistema, ou nem procuram novamente os serviços. Contudo, o acolhimento não se restringe ao primeiro contato. Permeia todos os encontros de uma pessoa pelos serviços, pois nunca se cessa efetivamente de investigar/elaborar/negociar necessidades que podem vir a ser satisfeitas pelo serviço, evocando sempre a incorporação das tecnologias leves/relacionais 32 .

Apesar da estratégia de acolhimento não ter sido implantada oficialmente no município, como preconiza a Política Nacional de Humanização em Saúde (PNHS) ${ }^{33}$, muitos/as profissionais da UBS pautam suas relações no atendimento a mulheres vítimas de violência doméstica em pressupostos dessa política: estabelecendo diálogos e buscando ativamente o problema, mesmo sem estrutura condizente para tal. Em relação ao ambiente para proporcionar o acolhimento, Teixeira 27 propõe todos os espaços, o papel de tudo receber, interligar e mover nessa rede, sendo o elemento que conecta uma conversa à outra, interconectando os diferentes espaços de conversa. Para ele, qualquer encontro trabalhador/ausuário/a, em qualquer conversa, não cessamos de acolher novas demandas que, eventualmente, convidam o sujeito a outros espaços e constituir outros diálogos. $\mathrm{O}$ acolhimento dialogado almeja manter todos esses espaços interconectados, oferecendo às pessoas as mais amplas possibilidades na rede. Assim, esse dispositivo permite que diferentes conversas se articulem em rede, formando um espaço coletivo de diálogos.

Sobre o diálogo entre mulheres em situação de violência doméstica e profissionais, destacase com base nesta pesquisa, o papel chave de ACS neste processo. Ao visitarem constantemente as pessoas sob seus cuidados, adentrando no universo doméstico, o diálogo se estabelece es- 
pontaneamente e mais horizontalmente (comparado a outros profissionais), embora nem sempre com facilidade. Também se pondera o fato de que ACS pertencem às comunidades, o que facilita o estabelecimento de relações mais empáticas e minimiza questões de assimetria de poder, que existem nas relações profissionais-usuárias/ os. Adicionalmente, o fato de ACS não receberem uma formação específica em saúde torna suas subjetividades, de certa forma, não tão agenciadas por elementos da biomedicina, como outras/ os profissionais. Ao visitarem rotineiramente e conversarem com as pessoas, podem ter uma visão geral das condições de saúde, principalmente de determinantes sociais, contribuindo para sua sensibilização para peculiaridades dos/ as usuários/as.

Portanto, a etnografia mostrou que profissionais de saúde e particularmente ACS podem desempenhar um significativo papel no acolhimento de mulheres em situação de violência doméstica. Tal iniciativa, desde que permeada por reflexões, pode constituir-se em uma estratégia de amparo às mulheres fragilizadas pela violência doméstica tanto em condições crônicas quanto em situações agudas, pois seguindo diretrizes da PNHS 33, se propõe a prevenir, cuidar, proteger, tratar, recuperar, promover, enfim, produzir saúde em uma ação de "estar com" e "estar perto de".

Teoricamente tais ponderações parecem razoáveis, mas na prática o desafio é grande e persistem hiatos entre discursos e práticas. Lacunas na formação/sensibilização para o acolhimento se intercruzam com a falta de estratégias efetivas para combate às relações de gênero desiguais. Apropriar-se do referencial de gênero poderia fazer as/os profissionais terem mais nitidez sobre o acolhimento? Como os conceitos e práticas se intercruzam? A ausência de estrutura do sistema, associada à exposição que profissionais de saúde estão sujeitos, revela a complexidade de situações/negociações que profissionais da atenção primária à saúde precisam dar conta. Em síntese, no campo das violências, as facetas se revelam entremeadas por nós górdios, não sendo simples desatá-los. Desse modo, ouvir profissionais que estão em contato direto com mulheres vítimas de violência doméstica torna-se imprescindível para iluminar teoria e prática em questão.

\section{Considerações finais}

Estudos sobre como profissionais de saúde atendem às mulheres vítimas de violência doméstica realçam que são muitos os desafios, constituindo-se tema complexo para o campo da Saúde Coletiva. Analisar as relações entre tais atores pode contribuir no incremento de políticas e práticas de saúde. Como ponto-chave, almejase considerar não apenas questões biológicas envoltas no problema, mas as diferentes condições sociais, econômicas, culturais, psicológicas e ambientais, realçadas ao longo deste artigo. Os estudos de gênero, além de problematizar a biologia, também foram confrontados com as experiências do campo. Tal conjunto, muitas vezes é desestimado por abordagens exclusivamente biologizantes, mas que também não merecem ser condenadas. Não se trata de adotar um modelo em detrimento ao outro, mas de valorizar potencialidades e reconhecer limitações de cada abordagem.

Esta pesquisa destacou atendimentos de profissionais de saúde às mulheres vítimas de violência doméstica que se tensionam entre alguns aspectos da biomedicina, de caráter mais biologizante e medicalizante, e o acolhimento em saúde, pautado em abordagens mais subjetivas, tendo o diálogo e o estabelecimento de vínculo como eixos estruturantes. Tais abordagens coexistem e foram destacadas com base na pesquisa etnográfica. Baseando-se nas acepções teóricas, foram realçadas ações profissionais que (mesmo pontuais e informalmente), por vezes, convergem com aquilo que vem sendo designado como acolhimento em saúde. As estratégias de profissionais da UBS de Matinhos foram trazidas à tona e cotejadas com a literatura, destacando-se que num sistema alicerçado sobre bases sólidas da biomedicina, percebem-se iniciativas que potencializam outros modos de cuidado às mulheres vítimas de violência doméstica.

Apesar de características atraentes envoltas na proposta de acolhimento, preconizadas por políticas públicas e descritas teoricamente, na rotina do SUS nem sempre isso corresponde totalmente à realidade. Ou seja, há hiatos entre discursos (academia/políticas) e práticas (serviços). Apesar de profissionais de Matinhos citarem frequentemente o acolhimento e identificados componentes dessa proposta com base na literatura, a gramática do acolhimento muitas vezes é distante das percepções de profissionais. Outra observação é que nem sempre tal abordagem parece ser condizente com os anseios da população, que em muitas circunstâncias preferem medicamentos, exames etc. Muitos desafios persistem, como por exemplo, lacunas estruturais e na for- 
mação/sensibilização sobre assimetrias de gênero e sobre o acolhimento em saúde. Ademais como pensar um cuidado centrado nas mulheres se o sistema é centrado nos/as profissionais, especialmente nos/as médicos/as? Como efetivar

\section{Resumen}

La violencia doméstica provoca múltiples repercusiones en la salud de las mujeres y genera una desafiante agenda para profesionales del SUS. El estudio tuvo por objetivo analizar cómo atienden los profesionales de salud a tales mujeres, problematizando la noción de acogida en salud. Se adoptó una investigación cualitativa y una aproximación etnográfica con profesionales de una unidad básica de salud (UBS) de Matinhos, Paraná, Brasil. La investigación reveló atención centrada en: (1) preceptos biologizantes, centrándose en lesiones físicas y medicalización; (2) diálogo, escucha activa, cuestiones psicosociales y establecimiento de vínculos, destacándose los agentes comunitarios de salud en este enfoque. La escasez de estructura local oficial para el manejo de la violencia doméstica da pie a la actuación inscrita bajo las tesis de la acogida, preconizada por el SUS, descrita por la literatura, verbalizada en la UBS, pero poco problematizada. Con este artículo se buscó, por tanto, contribuir con este debate, no en el establecimiento de prescripciones, sino en la realización de indagaciones y, principalmente, visibilizando y traduciendo voces de quien trabaja desde hace mucho tiempo con ese desafío.

Violencia Doméstica; Violencia Contra la Mujer; Género y Salud; Acogimiento o acolhimento, ouvindo, dialogando e criando vínculo, se existem poucos/as profissionais para dar conta de uma vasta população? Enfim, o desafio continua...

\section{Colaboradores}

M. C. Signorelli contribuiu no desenho do estudo, na condução da pesquisa de campo, escrita e revisão. D. Auad contribuiu no desenho do estudo, na revisão e no referencial teórico sobre gênero. P. P. G. Pereira contribuiu no desenho do estudo, no referencial teóricometodológico e na revisão.

\section{Agradecimentos}

Agradecemos à Coordenação de Pessoal de Nível Superior (Capes) pelo financiamento por meio de bolsa de estudos. 


\section{Referências}

1. Krug EG, Dahlber LL, Mercy JA, Zwi AB, Lozano R. World report on violence and health. Geneva: World Health Organization; 2002.

2. Garcia-Moreno C, Jansen HA, Ellsberg M, Heise L, Watts CH. Prevalence of intimate partner violence: findings from the WHO multi-country study on women's health and domestic violence. Lancet 2006; 368:1260-9.

3. Schraiber LB, D'Oliveira AFPL, França-Jr I, Diniz S, Portella AP, Ludermir AB, et al. Prevalência da violência contra a mulher por parceiro íntimo em regiões do Brasil. Rev Saúde Pública 2007; 41:797-807.

4. Scott J. Gender: a useful category of historical analysis. Am Hist Rev 1986; 91:1053-75.

5. Delphy C. Close to home: a materialist analysis of women's opression. London: Hutchinson; 1984.

6. Debert GG, Gregori MF. Violência e gênero: novas propostas, velhos dilemas. Rev Bras Ciênc Soc 2008; 23:165-85.

7. Pereira PPG. Violência, gênero e cotidiano: o trabalho de Veena Das. Cadernos Pagu 2010; 35:357-69.

8. Schraiber LB, D'Oliveira AFPL, Falcão MTC, Figueiredo WS. Violência dói e não é direito: a violência contra as mulheres, a saúde e os direitos humanos. São Paulo: Universidade Estadual Paulista; 2005.

9. McCauley J, Kern DE, Kolodner K, Dill L, Schroeder AF, DeChant HK, et al. The "battering syndrome": prevalence and clinical characteristics of domestic violence in primary care internal medicine practices. Ann Intern Med 1995; 123:737-46.

10. Camargo-Júnior KR. Biomedicina, saber \& ciência: uma abordagem crítica. São Paulo: Editora Hucitec; 2003.

11. Merhy EE, Campos GWS, Cecílio LCO, organizadores. Inventando a mudança na saúde. São Paulo: Editora Hucitec; 1994.

12. Franco TB, Bueno WS, Merhy EE. O acolhimento e os processos de trabalho em saúde: o caso de Betim, Minas Gerais, Brasil. Cad Saúde Pública 1999; 15:345-53.

13. Liamputtong P, Ezzy D. Qualitative research methods. 2nd Ed. Melbourne: Oxford; 2005.

14. Geertz C. The interpretation of cultures. New York: Basic Books; 1973.

15. Covolan NT, Oliveira DC, Signorelli MC. Violência doméstica contra mulheres no litoral do Paraná: olhares a partir um projeto de ensino/pesquisa/ extensão. In: Denardin VF, Abrahão CMS, Quadros DA, organizadores. Litoral do Paraná: reflexões e interações. Matinhos: UFPR Litoral; 2011. p. 39-49.

16. Souza PA, Ros MA. Os motivos que mantêm as mulheres vítimas de violência no relacionamento íntimo. Revista de Ciências Humanas 2006; 40:509-27.

17. Schraiber LB, D'Oliveira AFPL. Romper com a violência contra a mulher: como lidar desde a perspectiva do campo da saúde. Athenea Digital 2008; $14: 229-36$
18. Deeke LP, Boing AF, Oliveira WF, Coelho EBS. A dinâmica da violência doméstica: uma análise a partir dos discursos da mulher agredida e de seu parceiro. Saúde Soc 2009; 18:248-58.

19. Alpert EJ. Violence in intimate relationships and the practicing internist: new "disease" or new agenda? Ann Intern Med 1995; 123:774-81.

20. Warshaw C. Domestic violence: changing theory, changing practice. In: Monagle JF, Thomasma DC, editors. Health care ethics: critical issues for the 21st century. Gaithersburg: Aspen Publishers; 1998. p. 128-37.

21. Freund KM, Bak SM, Blackhall L. Identifying domestic violence in primary care practice. J Gen Intern Med 1996; 11:44-6.

22. Herrera C, Agoff C. Dilemas del personal médico ante la violencia de pareja en México. Cad Saúde Pública 2006; 22:2349-57.

23. Gover AR, Kaukinen C, Fox KA. The relationship between violence in the family of origin and dating violence among college students. J Interpers Violence 2008; 23:1667-93.

24. Oliveira MAS, Sani AI. A intergeracionalidade da violência nas relações de namoro. Revista da Faculdade de Ciências Humanas e Sociais 2009; 6:162-80.

25. Oliveira EM, Barbosa RM, Moura AAVM, von Kossel K, Morelli K, Botelho LFF, et al. Atendimento às mulheres vítimas de violência sexual: um estudo qualitativo. Rev Saúde Pública 2005; 39:376-82.

26. Silva-Júnior AG, Merhy EE, Carvalho LC. Refletindo sobre o ato de cuidar da saúde. In: Pinheiro $\mathrm{R}$, Mattos RA, organizadores. Construção da integralidade: cotidiano, saberes e práticas em saúde. Rio de Janeiro: Instituto de Medicina Social, Universidade do Estado do Rio de Janeiro/ABRASCO; 2003. p. 113-28.

27. Teixeira RR. O acolhimento num serviço de saúde entendido como uma rede de conversações. In Pinheiro RE, Mattos RA, organizadores. Construção da integralidade: cotidiano, saberes e práticas em saúde. Rio de Janeiro: Instituto de Medicina Social, Universidade do Estado do Rio de Janeiro/ ABRASCO; 2003. p. 89-111.

28. Ramos DD, Lima MADS. Acesso e acolhimento aos usuários em uma unidade de saúde de Porto Ale gre, Rio Grande do Sul, Brasil. Cad Saúde Pública $2003 ; 19: 27-34$.

29. Gomes MCPA, Pinheiro R. Acolhimento e vínculo: práticas de integralidade na gestão do cuidado em saúde em grandes centros urbanos. Interface Comun Saúde Educ 2005 9:287-301.

30. Ayres JRCM. O cuidado, os modos de ser (do) humano e as práticas de saúde. Saúde Soc 2004; 13:16-29. 
31. Camargo Jr. KR, Campos EMS, Bustamante-Teixeira MT, Mascarenhas MTM, Mauad NM, Franco TB, et al. Avaliação da atenção básica pela ótica político-institucional e da organização da atenção com ênfase na integralidade. Cad. Saúde Pública 2008; 24 Suppl 1:S58-68.

32. Merhy EE. Saúde: a cartografia do trabalho vivo. São Paulo: Editora Hucitec; 2002.
33. Núcleo Técnico da Política Nacional de Humanização, Secretaria de Atenção à Saúde, Ministério da Saúde. Acolhimento nas práticas de produção de saúde. 2a Ed. Brasília: Ministério da Saúde; 2006.

Recebido em 04/Out/2012

Versão final reapresentada em 19/Dez/2012

Aprovado em 01/Fev/2013 